\title{
CONTEXT MATTERS: STUDENT EXPERIENCES OF INTERACTION IN OPEN DISTANCE LEARNING
}

\author{
Dr. Geesje van den BERG \\ ORCID: 0000-0002-0306-4427 \\ College of Education \\ University of South Africa \\ Pretoria, SOUTH AFRICA
}

Received: 21/10/2019 Accepted: 11/05/2020

\begin{abstract}
An important factor in online learning is how students are afforded opportunities for interactions to create their own knowledge and attain high levels of student satisfaction. In open distance learning, three types of interaction were initially distinguished: interaction with content, with the lecturer and with fellow students. As technology plays an essential role in online learning, interaction with technology was added. This study was conducted at an open distance learning institution using a blended learning approach. Since it was the first fully online course for first-year Education students, the purpose of the study was to determine students' experiences of their learning in order to consider how offering the course online might affect their satisfaction and academic success. Within a connectivist paradigm, the research used a case study involving questionnaires with closed and open-ended questions. Findings confirmed the value of interaction on all levels and pointed towards the challenges in interaction with technology. Based on these findings, the study suggests that lecturers should consider the contexts of students when planning and designing online courses. As a result, it remains the university's responsibility to put systems in place to support and prepare students.
\end{abstract}

Keywords: Student interaction, context, open distance learning, student-centeredness, online learning.

\section{INTRODUCTION}

Open distance learning (ODL) is characterized by a separation between student and lecturer, the use of technology to facilitate teaching and learning and student-centeredness. Students who come from a conventional form of education that is structured and mostly teacher-centered, may find the transition to becoming an ODL student in a more unstructured, student-centered learning environment very challenging (Banna, Lin, Stewart \& Fialkowski, 2015). For this reason, Wang, Chen and Anderson (2014), as well as Tirri and Kuusisto (2013), state that interaction with both humans and technology is critical in building the necessary connections in virtual learning environments. The technology system itself should be seen as an environment that allows students to engage in learning-related activities at any time and from anywhere (Bouhnik \& Marcus, 2006). As an online course designer, Trentin (1998) indicates that the more accessible these environments are structured to meet students' communication needs, the more enjoyable and troublefree the interaction will be. In their online teaching, lecturers have to determine what the system has to offer to ensure that all types of interaction are enjoyable and useful.

Unlike face-to-face interaction, where instruction is synchronous, interaction in distance learning can be either synchronous or asynchronous (Ustati \& Hassan, 2013). This is an important difference, in the sense that immediate or synchronous interaction is set for a specific time and creates a feeling of belonging (Dzakiria, Rozhan \& Hanafi, 2005). The opposite may be true for asynchronous interaction - the interaction examined in the current study - where students may not have that sense of belonging and can easily feel isolated, which, in turn, can lead to a lack of motivation and dropout (Banna et al., 2015). On the other hand, asynchronous interaction has the advantage of providing students with more freedom and flexibility they can take control of when and how they prefer interaction with humans and the system. 
The concept of interaction is defined in various terms and no single definition exists. The term is associated with concepts such as cooperation, collaboration and active learning (Kenny, 2002). According to Muirhead and Juwah (2004), interaction as a multifaceted phenomenon, is about the personal nature of sharing information in the online classroom. Both Tait (2000) and Dzakiria, Kasim, Mohamed \& Christopher, (2013) claim that the greater the interaction, the better for the student, as well as for the teaching and learning process. This is also true for ODL courses, where interaction is seen as a challenging but critical aspect of distance learning (Dzakiria et al., 2013; Wang et al., 2014). Although research on student interaction has been documented within the ODL environment, there is no best-fit system for student interaction, since it remains highly context-based (Dzakiria et al., 2013). In fact, Woo and Reeves (2007) argue that the nature and frequency of interaction is dependent on the contexts in which these interactions occur, while Lee and Martin (2017) state that contextual factors have to be taken into consideration in online teaching and learning. Artino (2010) points out that although online learning is growing, little is known about the personal factors that influence online learning, while Naidu (2013, p.268) argues that "very little attention is paid to analyzing and understanding learners and their unique contexts before teaching and learning occurs". From the above, it is clear that several authors have emphasized the importance of context in student interaction. Yet, despite these statements, no study focusing on context in student interaction could be found and this paper intends to make a contribution in this regard.

Because of vastly different contexts, it does not make sense to generalize the profile of a typical ODL student. However, to establish a background for this paper, it is necessary to include a few comments on the context in which ODL students in general find themselves. These students differ in their dependence on interaction, according to their age, self-directedness and learning styles (Pavalache-Ilie \& Cocorada, 2014). Students who are more autonomous, may need and prefer less interactivity, while younger or first-year students may rely more on interaction (Dzakiria et al., 2005). ODL students often experience challenges in respect of ODL and interaction. One such challenge is the fact that, while there might be a need for frequent interaction, such interaction might not always be possible, especially for students who do not live in urban areas and do not have regular access to computers or the internet. Related to the lack of access, is the need for information and communication technologies (ICT) skills. This need, according to Kirlidog, Van der Vyver, Zeeman and Coetzee (2018), is dire in the South African context. Many students come from school environments where these skills were not taught or prioritized and it might, therefore, be a daunting task to get them to the point where they can competently use technology for success in their courses. Hillman, Willis and Gunawardena (1994) note that student success in ODL is related to their ICT proficiency and the ability to find and post the right information, while both Dzakiria et al. (2005) and Weidlich and Bastiaens (2018) caution that using the electronic medium can inadvertently exclude students who lack the necessary skills. A further challenge is that internet costs can be quite high, especially in a country such as South Africa, which is well known for its exorbitant internet costs (Oyedemi, 2015). High data costs result in an additional financial burden for the ODL student. Lecturers and other ODL stakeholders should be aware of students' challenges and realities which could impact on successful interaction.

\section{STUDENT INTERACTION IN ODL}

Moore (1989) was the first author to distinguish between three types of interaction, that is student-content interaction, student-teacher interaction, and student-student interaction in distance education. The three types of interaction have different effects on students and on the effectiveness of the teaching-learning experience (Dzakiria et al., 2005). Following Moore (1989), researchers such as Hillman et al. (1994) and Bouhnik and Marcus (2006) added a fourth type, namely interaction with the system, i.e. technology as a medium. More authors have provided variations and developments regarding types of interaction (see, for example, Anderson \& Garrison, 1998; Anderson \& Dron, 2007; Dron, 2007). However, for the purpose of this paper, the focus is on the four types of interaction and they are discussed in the subsequent paragraphs.

Interaction with content takes place when students, with the assistance of the lecturer, create new knowledge by combining new information with their existing knowledge. Without this kind of interaction, as in agreement with Bouhnik and Marcus (2006), no education takes place. Because this engagement is about communication between the author of the content and the reader, student-content interaction is regarded 
as interpersonal and interactive (Xiao, 2017). Student-content interaction can take many forms, such as watching instructional videos, interacting with multimedia, doing research and searching for information (Abrami, Bernard, Bures, Borokhovski \& Tamim, 2011). However, Hege (2011) correctly states that to create a vibrant online community, lecturers must facilitate students' engagement with the study material and assignments.

Coppola, Hiltz and Rotter (2002) assert that the three roles of lecturers, being cognitive, affective and to teach, are more complex in an online environment. The cognitive role shifts to deeper complexity, the affective role requires lecturers to find ways to express emotion and the teaching role requires more detail for structuring and monitoring of students to ensure that learning takes place and to prevent them from getting lost in the online environment. In her research, Swan (2002) found that instructors need to interact with students frequently to bridge the psychological and physical gap of distance learning. According to Bouhnik and Marcus (2006), interaction between students and lecturers leads to effective interaction with the content. However, student-lecturer interaction (which includes interaction with tutors and teaching assistants) can be regarded as expensive and demanding since it requires the online presence of the lecturer and extensive involvement in course facilitation (Anderson, 2003). Yet, Anderson points out that the advancement of technology has, in some instances, enabled the replacement of student-lecturer interaction with studentcontent interaction by offering information in different formats, such as video and audio. These statements confirm that the different kinds of interactions are interdependent and that the relationship is complex.

In their research, Yu, Tian, Vogel and Kwok (2010) found that discussions amongst students not only affected learning outcomes positively, but that such discussions also assisted them in gaining social acceptance and adapting to the university culture. Banna et al. (2015) point out that since research has indicated that students learn better in groups than on their own, student-student interaction is particularly significant in promoting an online environment. Furthermore, according to Woo and Reeves (2007), learning occurs through communication with peers sharing the same context and real-life experiences. One of the most influential features in asynchronous learning courses is interaction between students through discussions (Bouhnik \& Marcus, 2006). In online discussions, every student has a voice, and neither the lecturer nor a student can dominate the conversation. Swan (2002) adds that online group discussions are more equitable and democratic than face-to-face discussions and can lead to further opportunities for reflection, mindfulness and a sense of belonging.

The three kinds of interaction, described above and prevalent in the online learning environment, are mediated by an underlying technology. Interaction with technology is therefore a further vital type of interaction that needs to be added to Moore's initial three types of interaction. Interaction with an increasingly interactive system, where students can interact with machines and digital artefacts, has changed the way in which lecturers teach and the way in which students learn, forcing the whole world into a different way of doing things. Bouhnik and Marcus (2006) explain that learning is complex but that the benefits of the technological system can easily be lost if not dealt with satisfactorily. They further state that even if the technology is utilized to its fullest, there is no guarantee that it will add quality to the learning process. It is therefore vital that technology supports teaching and learning, be fully functional and not become a psychological or functional barrier. In their study, Kedar, Baruch and Gruvgald (2003) found that if the technical problems that students encounter are not addressed immediately, this will negatively impact on their learning experiences. Support should therefore be available to assist students as quickly as possible.

\section{PURPOSE OF THE STUDY}

The University of South Africa (UNISA), which previously was a paper-driven distance education institution, is currently following a blended approach and is progressively moving to an online model of teaching and learning. As a result, learning is facilitated through multiple teaching and learning strategies, a range of technologies in combination with face-to-face interaction and the deployment of both physical and electronic study material (UNISA, 2008). Not all students have regular access to the internet, therefore they receive electronic as well as hard copies of study material to ensure that no one is disadvantaged. However, the University is moving towards a delivery model with more online courses and programs. Part of this process is to facilitate channels for students to have access to electronic devices and processes, and 
procedures have been put in place to ensure connectivity and support to students (UNISA, 2018). The learning management system (LMS) at the University (the Sakai platform, known as myUnisa) is a teaching, learning and administrative tool and is the official mode of online communication with students. Since more courses are gradually being offered online, it was necessary to discover how students experience this environment. Xiao (2017) confirms that much more understanding is needed of the role, as well as the functionality of interaction in ODL, and how it affects students' learning experiences and satisfaction. This paper is intended to offer a contribution in this regard, its purpose being to describe students' experiences of a first-year fully online course within a specific teaching and learning context. It is important to listen to students' voices to understand their educational experiences. Only then can lecturers and instructional designers develop online courses that meet students' needs, in order to improve their online interactions and ultimately, facilitate their learning.

The intention of this study was to document how students experience their interaction with their peers, lecturers, the course content, and technology within the ODL context.

\section{THEORETICAL FRAMEWORK}

Interaction has been a highly valued key concept in distance learning since the earliest generations of correspondence distance education (Taylor, 2001). With the continuing development of interaction and interactive technologies, online learning has developed from having cognitive behavioral pedagogical roots, to socio-constructivist learning and most recently to connectivist learning (Wang et al., 2014). As opposed to other learning theories, connectivism is about interaction between the student and different knowledge sources: other people, groups sharing the same interests, the internet and learning management systems (Pavalache-Ilie \& Cocorada, 2014). This paper is therefore framed within the connectivist learning theory, assuming that learning takes place because of and by means of these interactions which take place between humans and between humans and technology (Downes, 2007). Siemens (2005) and Downes (2007) developed this relatively recent pedagogical theory to understand learning in a digital and connected world. The connectivist learning theory has had an impact on teaching and learning practices, making knowledge distribution possible to all network members (Van den Berg, 2017). In this regard, Siemens (2006) argues that knowledge has changed from categorization and hierarchies to networks and ecologies. We currently exist in a knowledge society, implying that our lives focus on the creation, communication and application of knowledge. Connectivism is therefore not only about transferring or building knowledge, it is also about interactions or connections to facilitate learning and development. Siemens (2006) states that these connections are fluid, adaptive and vary in size and scope. Connectivism plays a vital role in the development of new pedagogies, where control is shifted from the lecturer to an increasingly independent student (Kop \& Hill, 2008). Wagner (1994, p.8) states that "interactions are reciprocal events that require at least two objects and two actions". This definition of interaction implies reciprocal events between students and technology, between living and non-living entities in physical and digital spaces, which is an important notion in connectivist learning (Wang et al., 2014). Different interactions are necessary for connection building, which deepens and creates different layers of learning. According to Siemens (2006), learning is not always about learning new content, but to be able to access sources of knowledge when it is needed. In a world that grows and continuously produces new knowledge, it is this access to the sources that is an asset to the student and positions him/her as a lifelong learner (Bozkurt, Honeychurch, Caines, Bali, Koutropoulos \& Comier, 2016). Within this connectivist framework, the focus of the interactions discussed in this paper is pedagogical in nature. Against this background, the next section explains the methodology of the empirical research.

\section{METHODOLOGY}

\section{Research Design}

This study is part of a larger research project to evaluate online courses at UNISA. Within a connectivist research paradigm, the study followed a case study design to determine students' experiences of an online course. Data was collected quantitatively as well as qualitatively, therefore a mixed-mode approach was used. 


\section{Participants and Context}

Students, who were enrolled for a first-year online semester course at the College of Education at UNISA, participated in this study and were involved and treated as an exemplary (sample) case of similar online courses at the University. The study was conducted in the second semester of 2018, after the students had completed the first two of a total of six assignments. Besides exposing students to working within an online learning environment, the course content focused on teaching the values, roles and responsibilities of a professional school teacher. The students were grouped into virtual classes of between 40 and 50 students, with a teaching assistant to act as a learning facilitator and assessor and continued for 16 weeks, which is the duration of this semester course. In using the LMS as the teaching and learning platform, students were able to interact freely with their fellow students and teaching assistants in the discussion forums.

\section{Research Instrument}

In order to establish how students experienced this first-year online course, a questionnaire with five biographical and 27 open and closed questions related to various aspects of their online course was sent to all students enrolled for the second semester of the 2018 academic year. Because open and closed questions were used to elicit quantitative and qualitative data, a mixed-method approach was used. Open question responses lead to qualitative analysis, while the closed question responses were analyzed quantitatively. Out of the 7030 questionnaires, a total of 358 responses $(5.09 \%)$ were received. The low response rate can be attributed to the formal nature of the e-mail sent to the students as official university correspondence, incorrect or invalid e-mail addresses on the university administrative system and personal reasons of working students.

The instrument of data gathering was the question "How do you feel about this online course?" This question had a closed response, framed to elicit answers on a five-point Likert scale, ranging from "dislike extremely" to "like extremely", while in the second part of the question, which was the open-ended part, students were asked to explain their choice of the first answer.

\section{Procedures}

Before the study commenced, ethical clearance and permission to conduct the research were granted by UNISA. Students were informed that their participation in the study was voluntary and that their identity would be kept confidential at all times. To ensure the internal validity and reliability of the instrument, it was piloted and tested with ten students who were enrolled in an online module in a different college at the university, and who were therefore not part of the research. Saunders, Lewis and Thornhill (2009) argue that prior to using a questionnaire to collect data, it should be piloted with a minimum number of ten participants to refine the instrument. Based on their feedback, a few minor changes were made to improve the instrument. Because of the low response rate, the external validity of this study is at stake. However, the purpose was not to generalize the results of the current study to the world at large, but to learn more about a specific group of students' experiences of an online course. UNISA offers a number of similar online courses in its various colleges. It also has the purpose of initial research that could be followed up with more qualitative research.

The Statistical Package for the Social Sciences (SPSS) was used for data analysis, to calculate frequency distributions. The qualitative data was analyzed using content and thematic analysis. According to Braun and Clarke (2006), thematic analysis can be described as a method for identifying, analyzing and reporting on patterns. Commonly occurring and prevalent themes were identified to assist in answering the research question about the students' experiences of online interaction.

Responses from students were categorized into four themes:

- Interaction with fellow students

- Interaction with lecturers

- Interaction with content

- Interaction with the system 


\section{FINDINGS AND DISCUSSION}

\section{Quantitative Analysis}

Of the 358 responses received, 290 (81\%) students were female and 68 (19\%) male. The low number of male students is congruent with local trends in student enrolments in education. For example, in 2017, 29,3\% of education students enrolled at universities were male, while 70,7\% were female (Statistics SA, 2019).

The age distribution of the participants is indicated in Table 1.

Table 1. Responses by age group

\begin{tabular}{ccc}
\hline Age group & Response $(\mathrm{N}=358)$ & \% Student responses \\
\hline $18-24$ & 192 & $53.6 \%$ \\
$25-29$ & 87 & $24.3 \%$ \\
$30-34$ & 37 & $10.3 \%$ \\
$35-39$ & 21 & $5.9 \%$ \\
$40-44$ & 13 & $3.6 \%$ \\
$45+$ & 6 & $1.7 \%$ \\
\hline
\end{tabular}

This information was relevant, specifically because most students (77.9\%) were under the age of 30 and can therefore be regarded as familiar with access to and the use of entrenched technologies such as computers, email and smartphones (Kennedy et al., 2008). In addition, many of these students had recently left school where they were introduced to technology and developed ICT knowledge and skills and as such, could easily adapt to an ODL environment.

Of the 358 participants who submitted questionnaires, 243 (68\%) indicated that they were part-time students, while $114(32 \%)$ were studying full time. Since most students were working and studying, they might have had the additional burden of balancing their work life, their family life and their studies, as found in previous studies by Carney, McNeish and McColl (2005) and Erasmus and Grebe (2016).

The first part of the question was based on a five-point Likert scale, ranging from "dislike extremely" to "like extremely".

Table 2. Frequency of participants' responses on how they felt about the online course

\begin{tabular}{lcc}
\hline Response & Response (N=358) & \% Student responses \\
\hline Dislike extremely & 9 & $2.2 \%$ \\
Dislike very much & 13 & $3.6 \%$ \\
Neither like or dislike & 71 & $18.8 \%$ \\
Like very much & 189 & $52.8 \%$ \\
Like extremely & 76 & $21.2 \%$ \\
\hline
\end{tabular}

The results show that most students liked the online course (74\%), while some neither liked nor disliked it $(18.8 \%)$, and a few $(6.6 \%)$ did not like it at all. The second part of this question asked students to explain their answers. The analyses of student responses were categorized according to the four categories of interaction, i.e. with students, lecturers, content and with the system.

\section{Qualitative Analysis}

The written responses substantiating the students' choices on the Likert scale question were coded and categorized and will be discussed next under each of the four themes. 


\section{Interaction with Fellow Students}

The written responses showed that the students were appreciative of the assistance they received from their peers. Assistance was articulated in terms of social and emotional support, learning support, knowledge gained and opportunities to participate in online debates. Regarding social and emotional support, one student stated: "By having the course online, we have support from other students doing the same subject instead of having to complete it on our own, especially when we are struggling", while another student referred to "the respect and kindness from my fellow students when I need help". Apart from the social and emotional support, students referred to the learning support they received, indicating the knowledge they gained from other students, their participation in debates and sharing different views and ideas. For example, a student said: "Initially I was not sure if I was on the right track, but after discussions with a few of my classmates, I received the confirmation I needed. It gave me confidence to complete the rest of my assignment". Such positive student responses about interactions with fellow students are in line with the results from a study by Agudo-Peregrina, Iglesias-Pradas, Conde-González and Hernández-García (2014), showing that students' academic performance in online learning mostly depended on student-student interactions.

Students who reported a positive online experience, also substantiated their feelings with references to group membership. They indicated that they were grateful to belong to a group. The following is an example of such a statement:

This is my first online course and I enjoy every moment - as I am sitting in my room at home on my own, I do not feel alone or overwhelmed by the thought of going through this on my own. I am part of a group and can ask questions anytime.

In explaining the view that they found interactions with fellow students valuable, references were made to a free and safe environment, where students felt that they could participate freely and learn from others. This is evident in the following example:

I was communicating with different people even if I didn't know them. But because of the way in which we were communicating, I felt I knew them.

In addition, students affirmed that they felt safe to communicate within their group, although they sometimes lacked confidence, especially at the beginning of the course. When referring to their interaction in groups, terms such as "cooperate", "interact", "communicate", "connect" and "participate" were used. These comments show students' "sense of belonging", which, as Dzakira et al. (2005) state, is sometimes difficult to achieve in distance learning.

However, students' interaction with their peers was not always perceived as positive, as 22 out of the total of 358 participants made remarks indicating that they did not always have good experiences. The responses showed that some students had difficulty in their interaction with fellow students. Exemplary explanations included a statement about a fellow student being "rude" and another one who constantly changed the subject to "political issues". Other responses showed that students' online experiences were in some cases negative, with remarks about this interaction being "useless", and maintaining that "it's just a bunch of random people posting random comments just to be able to say that they have participated in the discussions". Another response was:

I don't like doing things online, for example, chatting or discussing something with other students. I know I can perhaps learn something from them, that it saves time and money, but I just don't enjoy it.

The comment above shows that it cannot be taken for granted that students need or want interaction with fellow students and confirms the statement of Muirhead and Juwah (2004) recognizing the fact that the need for interaction is dependent on students' style of learning and their specific contexts. 
From the findings of the students' interaction with fellow students, it is significant to note that not all students had similar experiences and that the findings were diverse. For instance, while most students appreciated interaction with their fellow students, some found it problematic and preferred not to interact. In their study, Pavalache-Ilie and Cocorada (2014), found that students are comfortable to participate in an online learning environment, but that it depends on factors such as students' contexts and their level of self-directedness. Furthermore, students interact and access knowledge when it is needed, which refers to the complexity of these interactions, but also to the fact that learning is fluid, adaptive and that it varies in size and scope (Siemens, 2006). For instance, a self-directed, independent student does not necessarily need or prefer interaction with fellow students (Pavalache-Ilie \& Cocorada, 2014).

\section{Interaction with Lecturers}

Of the 265 student participants who responded positively on their experiences of the online course, the majority said that they received frequent communication from their lecturers (who were academics responsible for the course design, as well as for teaching on the LMS) or teaching assistants (who were working under the supervision of the lecturers and who were responsible for group teaching and the assessment of students' work). These students were satisfied with the interaction with their lecturers and teaching assistants and used terms such as "always available", "excellent", "amazing" and "helpful" when referring to such communication. In this regard, one student stated:

I have asked many questions to my teaching assistant, especially in the beginning of the semester. I was not familiar with myUnisa and had no confidence to study online. But my teaching assistant gave me confidence, she responded to my questions and gave me the guidance I needed. Now I can say that I enjoy this course.

Another student said that the teaching assistant continuously monitored their progress, and that they appreciated it, because it showed that the lecturer was concerned about their success, while another one said, "the teaching assistant is always there for me". Similar results came from studies by Arbaugh and BenbunanFich (2007) and Marks, Sibley and Arbaugh (2005), showing that the most significant predictors of student success were student-lecturer interactions. These authors further argue that students must be sufficiently engaged to ensure that they successfully complete their courses.

The findings of this research, however, showed that 12 students were not always satisfied with the level of interaction with their lecturers. In this regard, one student argued:

It is fine to learn online, but I would have liked to get better responses from my lecturer, on time and with good guidance. In the beginning of this course I was unsure what to do and where to start. I asked many questions but did not always receive prompt responses. This was demotivating.

Another student indicated that the lecturer was "not always available". This lack of the necessary lecturer support shows the importance of lecturer facilitation in online learning, as confirmed by both Swan (2002) and Hege (2011).

From the above, it is clear that most students experienced interaction with their lecturers as sufficient, while others needed more guidance or found that their lecturers were not always available when they needed them.

\section{Interaction with Content}

Since the course content was about being a professional teacher, students, in their explanations of their online experiences, mostly referred to the content related to the course. A student made the following comment: "...(I)t refers to so many aspects of teaching as a profession; I was not aware of some of them until I did this course. The study material was accessible on the site, and I could easily look up information when I needed it for my assignments". Another student mentioned that the online teaching methods were found to be useful. 
Students who indicated that they were positive about their online experiences with their course material, described this course as "interesting", "nice", "easy", "time-saving", "less stressful", "innovative", "mindprovoking", and most students indicated that they were positive about the online course. Furthermore, one student stated:

The online course is manageable, and I enjoy having everything online. It is easy to access content and videos when I need it. I enjoy this course.

On the other hand, several responses showed that students were not always positive about the course or found it easy. One student said: "I tried so hard to understand this online course, but it is difficult", while another student stated: "I didn't understand some things and it was not always explained very well online". Yet another student said that he/she disliked the course because it was online and working with books was so much easier.

Additionally, time was a factor for some students. Because this course had more assignments (six in total) than most semester courses for which the students are enrolled (generally two assignments), a total of 42 students mentioned that they struggled to complete their assignments on time. This shows that students need sufficient information and guidance regarding the number of assignments, as well as the time needed to complete an online course, especially when they are enrolled in a first-year course.

The participants indicated the different skills they gained, such as "self-study", "searching for information on the internet", "computer skills to access my materials" and "using videos". Some students referred to the saving of costs by not having to buy textbooks. This specific course only had online resources, of which most were open education resources (OERs) and therefore free to access.

From the responses, it was evident that this was the first online course undertaken by many of the students and thus a new experience. In this regard, one student said

\section{At first, I was intimidated by the online medium of this course, because it is my first fully online course, but once I got started, I found this approach refreshing.}

The fact that several students referred to the course as a new experience, and indicated that they had struggled at first, shows the importance of lecturer support and facilitation from the start of the course.

The findings on students' interaction with content indicated that most students had positive experiences during this course, but that there were also some students who stated that they did not enjoy the online environment, found the course difficult and found studying on paper easier. Likewise, while some found that studying online saved time, others indicated that they struggled to find enough time to study online. In their study, Muirhead and Juwah (2004) found that the level and the context of a course have a significant impact on interaction types, which is relevant to this study in the sense that the findings showed that some students needed a substantial amount of support, while others were comfortable to study on their own.

\section{Interaction with the System}

An online course depends on effective interaction with a system. In explaining their positive experiences of online learning, students expressed appreciation for the fact that they could do their work on their own devices, "from anywhere, at any time", and a student also referred to "the flexibility of online learning". These student statements correlate with a study by Weidlich and Bastiaens (2018) indicating that convenience and flexibility regarding the time and location of learning are often put forward as major advantages of online learning. A few students further highlighted other advantages of interaction with the system, such as the fact that the computer did automatic correction of spelling, which is a plus for non-native speakers of English, and the time they were saving because "I can do everything online". Additionally, a student said, "The learning units contain internet links and relevant local teaching advice. It is really just better to present a course this way." 
However, a total of 42 students indicated that sufficient time was a problem, because they did not have computers or internet connectivity at home and had to go to a facility like a Unisa regional center, internet cafe or public space for internet access. A student said,

I battle to get a chance to go to the internet cafe because I am volunteering at a school full-time and some things like the brochure we had to do for an assignment could not be done on my phone. Also, I do not have in-depth knowledge of a computer.

The student above not only had difficulty finding sufficient time to access a computer/the internet, but also lacked the necessary ICT skills, thus confirming the view of Shi, Shen and Tian (2010) that online students need to possess a medium or high level of confidence in utilizing the internet in order to perform online tasks and interact with others. Another student said, "The online course is fine, but sometimes it is difficult because not all of us have access to computers and the internet. "Within the South African context, Kirlidog et al. (2018) indicate that the country has a need for more people with adequate ICT skills. This particular student above, used his/her cell phone to access the course, resorting to mobile learning. The student was not the only one in this position, with another one confirming, "I could access the course information on my phone and tablet". In total, 18 students confirmed that they used their mobile devices to access their courses. These comments should make lecturers aware that online courses should be designed for use on different devices.

Related to limited access to devices and the internet, was the lack of enough data. One student stated that "the online course made things easy for me and I knew that all my assignments were safely received, but I spent all my money on data bundles". Several students had similar concerns about the lack of money for sufficient data.

Although many students gave positive feedback about their online learning experiences, others found the navigation challenging. For example, one student said, "I feel that more guidance should be given on how to start, where to start and especially on the final portfolio submission".

Another challenge that students experienced, was accessibility to the University's LMS. Students stated that the system was not always available. For example, one student said: "myUnisa is sometimes offline and then I cannot submit my assignments. This is frustrating us". This means that student-system interaction was not satisfactory, which has a negative effect on students' motivation and learning experiences in general. In this regard, studies by both Muirhead and Juwah (2005) and Joksimović, Gaševic, Kovanović, Riecke and Hatala (2015) show that positive and frequent student-technology interaction was the most important predictor of positive learning outcomes. This further concurs with both Arbaugh and Benbunan-Fich (2007) and Muirhead and Juwah (2004) that successful online learning requires high levels of digital proficiency, as well as user-friendly systems to support student-system interaction.

A significant specific finding of this study is the fact that students found it expensive to have internet connectivity and some of the comments imply that students had difficulty finding the money to buy data. If students do not have sufficient internet connectivity, connections with either human beings or technology is impossible, and interaction and learning cannot take place.

\section{RECOMMENDATIONS}

This study revealed that the contexts of students differ and that ODL institutions cannot take it for granted that all their students have the necessary knowledge and skills needed for online learning. It is therefore recommended that institutions ensure that their students, specifically first-year students with inadequate experience, are appropriately prepared for online learning when they enroll for an online course. Such student preparation can be, for example, a general ICT induction course at the beginning of their studies or an introductory first part to each course for which students enroll.

The findings of the study also showed that students need to have connectivity to the internet and enough data to access information. The study therefore recommends that students should be able to visit their university's website and their courses for free. Agreements with local service providers can assist universities to ensure that students do not have to add large amounts of unexpected data costs to their study fees. 
Lastly, the purpose of the study was to find out how students experience interaction in an ODL context. The findings revealed that students' experiences and needs differ, depending on their contexts. Instructors should therefore gather the necessary information about their students to ensure that courses make provision for these different contexts. By doing so, students can benefit optimally from their online interactions during their studies.

\section{CONCLUSION}

This study reports on students' experiences of an online course and the findings confirmed that most students were positive about their experiences and found the interaction during the course useful. This means that interactions have taken place between students and different sources of knowledge: between living and nonliving entities in digital spaces, which Wang et al. (2014) regard as an important part of connectivist learning. Students' interaction with their fellow students, the content, the lecturer and the system provide the pedagogical foundation for effective teaching and learning in an ODL environment, especially because of the physical separation between the student and the lecturer. This study further confirmed that during these interactions every student, every institution and every curriculum is unique, and each exhibits a unique context with differing strengths and weaknesses. While the strengths need to be embraced, lecturers and stakeholders at universities must be aware of possible weaknesses and challenges, with students' unique contexts being taken into consideration when planning and designing online courses. It remains a university's responsibility not only to put systems in place, but also to provide the necessary online training and support for its students. Only then will students be in a position to benefit optimally from operating in a connectivist learning environment, enabling them to be lifelong learners.

This study focused on students involved in only one online course in teacher education at one university and does not reflect the entire population. It should, however, serve as a basis for further studies concerning the importance of context in different online courses at different institutions.

Acknowledgements: The Bureau for Market Research at the University of South Africa provided the initial quantitative research data.

\section{BIODATA and CONTACT ADDRESSES of AUTHOR}

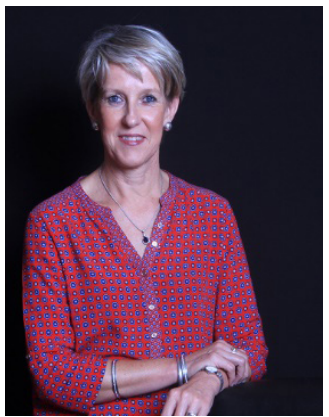

Dr. Geesje van den BERG is a professor in the Department of Curriculum and Instructional Studies at The University of South Africa. She obtained her DEd in Curriculum Studies in 2005 and currently teaches in the Master's in Education in Open Distance Learning (ODL) program. She has supervised more than 30 master's and doctoral students to completion in the fields of ODL and curriculum studies. She serves on the Editorial Boards of one local and two international scientific journals in Education. Her research interests and publications focus on topics related teaching and learning in online and open distance learning environments.

Geesje van den BERG

Department of Curriculum and Instructional Studies, College of Education Address: University of South Africa, PO Box 392, Unisa, 0003, Pretoria, South Africa Phone: +27 124294895

E-mail:vdberg@unisa.ac.za 


\section{REFERENCES}

Abrami, P. C., Bernard, R. M., Bures, E. M., Borokhovski, E., \& Tamim, R. M. (2011). Interaction in distance education and online learning: Using evidence and theory to improve practice. Journal of Computing in Higher Education, 23, 83-103.

Agudo-Peregrina, A. F., Iglesias-Pradas, S., Conde-González, M. A., \&Hernández-García, A. (2014). Can we predict success from log data in VLEs? Classification of interactions for learning analytics and their relation with performance in VLE-supported F2F and online learning. Computers in Human Behavior, 31, 542-550.

Anderson, T. (2003). Getting the mix right again: An updated and theoretical rationale for interaction. The International Review of Research in Open and Distance Learning, (4), 2. Retrieved September 4, 2018, from https://0-search-proquest-com.oasis.unisa.ac.za/docview/1634543750/ A38D3C92A1824B3BPQ/7? accountid $=14648$

Anderson, T., \& Dron, J. (2007). Groups, networks and collectives in social software for e-learning. Paper presented at 2007 European Conference on E-Learning, Copenhagen, Denmark.

Anderson, T., \& Garrison, D. R. (1998). Learning in a networked world: New roles and responsibilities. In C. Gibson (Ed.), Distance learners in higher education (pp. 97-112). Madison, WI.: Atwood Publishing.

Arbaugh, J., \& Benbunan-Fich, R. (2007). The importance of participant interaction in online environments. Decision Support Systems, 43(3), 853-865.

Artino Jr, A. R. (2010). Online or face-to-face learning? Exploring the personal factors that predict students' choice of instructional format. The Internet and Higher Education,13(4), 272-276.Banna, J., Lin, M. G., Stewart, M., \& Fialkowski, M.K. (2015). Interaction matters: Strategies to promote engaged learning in an online introductory nutrition course. MERLOT Journal of Online Teaching and Learning, 11(2), 249-261.

Bouhnik, D., \& Marcus, T. (2006). Interaction in distance-learning courses. Journal of the Association for Information Science and Technology, 57(3), 299-305.

Bozkurt, A., Honeychurch, S., Caines, A., Bali, M., Koutropoulos, A., \& Cormier, D. 2016. Community tracking in a cMOOC and nomadic learner behavior identification on a connectivist rhizomatic learning network. Turkish Online Journal of Distance Education, 17(4):4-30.

Braun, V., \& Clarke, V. (2006). Using thematic analysis in psychology. Qualitative Research in Psychology, 3(2), 77-101.

Carney, C., McNeish S. \& McColl, J. (2005) The impact of part time employment on students' health and academic performance: a Scottish perspective, Journal of Further and Higher Education, 29:4, $307-$ 319, DOI: $10.1080 / 03098770500353300$

Coppola, N., Hiltz, S., \& Rotter, N. (2002). Becoming a virtual professor: Pedagogical roles and asynchronous learning networks. Journal of Management Information Systems, 18(4), 161-189.

Downes, S. (2007). What Connectivism Is. Paper presented at the Online Connectivism Conference, University of Manitoba. Retrieved January 24, 2018, from http://ltc.umanitoba.ca/moodle/mod/forum/discuss.php?d=12 Dron, J. (2007). Control and constraint in e-learning: Choosing when to choose. Hershey, PA.: Information Science Pub.

Dzakiria, H., Kasim, A., Mohamed A. H., \& Christopher, A. A. (2013). Effective learning interaction as a prerequisite to successful Open Distance Learning (ODL): A case study of learners in the northern state of Kedah and Perlis, Malaysia. The Turkish Online Journal of Distance Education, 14(1), 111-125.

Dzakiria, H., Rozhan, M. I., \& Hanafi, A. (2005). Interaction in Open Distance Learning: Research issues in Malaysia. Malaysian Journal of Distance Education, 7(2), 63-77. 
Erasmus, C.F. \& Grebe, G.P.M. 2016. Availability of Study Time for Undergraduate Finance Students at an Open and Distance Learning Institution in South Africa. Journal of Higher Education in Africa I Revue de l'enseignement supérieur en Afrique, 14 (1): 141-154

Hege, B. A. R. (2011). The online theology classroom: Strategies for engaging a community of distance learners in a hybrid model of online education. Teaching Theology and Religion, 14(1), 13-20.

Hillman, D. C. A., Willis, D. J., \& Gunawardena, C. N. (1994). Learner-interface interaction in distance education: An extension of contemporary models and strategies for practitioners. American Journal of Distance Education, 8(2), 30-42.

Joksimović, S. Gaševic, D., Kovanović, V., Riecke, B. E., \&Hatala, M. (2015). Social presence in online discussions as a process predictor of academic performance. Journal of Computer Assisted Learning, 31(6), 638-654.

Kedar, T., Baruch, R., \&Gruvgald, E. (2003). Satisfaction from the e-learning system. Unpublished manuscript, Bar-Ilan University, Ramat Gan, Israel.

Kennedy, E.K., Judd, T.S., Churchward, A. \& Gray, K. 2008. First year students' experiences with technology: Are they really digital natives? Australasian Journal of Educational Technology, 24(1): 108-122.

Kenny, A. (2002). Online learning: Enhancing nurse education? Journal of Advanced Nursing, 38, 127-135.

Kirlidog, M., Van der Vyver, C., Zeeman, M., \& Coetzee, W. (2018). Unfulfilled need: Reasons for insufficient ICT skills in South Africa. Information Development, 34(1), 5-19.

Kop, R., \& Hill, A. (2008). Connectivism: Learning theory of the future or vestige of the past? The International Review of Research in Open and Distance Learning, 9(3). Retrieved October 4, 2018, from http://www.irrodl.org/index.php/irrodl/article/view/523/1103

Lee, J., \& Martin, L. (2017). Investigating students' perceptions of motivating factors of online class discussions. International Review of Research in Open and Distributed Learning, 18(5), 148-172.

Marks, R. B., Sibley, S. D., \& Arbaugh, J. B. (2005). A structural equation model of predictors for effective online learning. Journal of Management Education, 29(4), 531-563.

Moore, M.G. (1989). Three types of interaction. The American Journal of Open Distance Learning, 3(2), 1-6.

Muirhead, B., \& Juwah, C. (2004). Interactivity in computer-mediated college and university education: A recent review of the literature. Educational Technology \& Society, 7(1), 12-20.

Naidu, S. (2013). Instructional design models for optimal learning. In M.G. Moore (Ed.),Handbook of distance education(pp. 268-281). New York: Routledge

Oyedemi, T. (2015). Participation, citizenship and internet use among South African youth. Telematics and Informatics, 32(1), 11-22.

Pavalche-Ilie, M. \& Cocorada, S. (2014). Interactions of students' personality in the online learning environment. Procedia - Social and Behavioural Sciences, 128, 117-122.

Saunders, M., Lewis, P. \& Thornhill, A. (2009). Research methods for business students. Fifth Edition. India: Pearson Education.

Shi, J., Chen, Z., \& Tian, M. (2010). Internet self-efficacy, the need for cognition, and sensation seeking as predictors of problematic use of the Internet. Cyberpsychology, Behavior, and Social Networking, 14(4), 231-234. doi:10.1089/cyber.2009.0462

Siemens, G. (2005). Connectivism: A learning theory for the digital age. International Journal of Instructional Technology and Distance Learning, 2(1), 3-10.

Siemens, G. Knowing Knowledge. (2006). Vancouver, Canada: Lulu Press.

Statistics SA. (2019). Education Series Volume V: Higher Education and Skills in South Africa, 2017. Pretoria: Statistics South Africa. 
Swan, K. (2002). Building learning communities in online courses: the importance of interaction, Education, Communication and Information, 2(1), 23-49.

Tait, A. (2000). Planning student support for open and distance teaching. Open Learning, 15(3), 287-299.

Taylor, J. C. (2001). Fifth generation distance education. Retrieved from http://www.usq.edu.au/users/taylorj/ conferences.htm (accessed on 25/01/2018)

Tirri, K., \&Kuusisto, E. (2013). Interaction in Educational Domains. Sense Publishers.

Trentin, G. (1998). Computer conferencing systems as seen by a designer of online courses. Educational Technology, 38(3), 36-43.

UNISA. (2008). Open distance learning policy. Pretoria: UNISA.

UNISA. (2018). Policy on the provision of e-devices for e-learning at UNISA. Pretoria: UNISA

Ustati, R., \& Hassan, S.S.S. (2013). Distance learning students' need: Evaluating interactions from Moore's Theory of Transactional Distance. Turkish Online Journal of Distance Education, 14(2), 292-304.

Van den Berg, G. (2017). Learning theories and the use of technology in the classroom. In Swart, E. and Eloff, I. (Eds), Understanding educational psychology (pp. 69-76). Cape Town: Juta. ISBN9781485102472.

Wagner, E. D. (1994). In support of a functional definition of interaction. The American Journal of Distance Education, 8(2), 6-26.

Wang, Z., Chen, L., \& Anderson, T. (2014). A framework for interaction and cognitive engagement in connectivist learning contexts. The International Review of Research in Open and Distributed Learning, 15(2). doi:http://dx.doi.org/10.19173/irrodl.v15i2.1709

Weidlich, J., \& Bastiaens, T.J. (2018). Technology matters - The impact of transactional distance on satisfaction in online distance learning. International Review of Research in Open and Distributed Learning, 19(3), 222-242

Woo, Y., \& Reeves, T.C. (2007). Meaningful interaction in web-based learning: A social constructivist interpretation. Internet and Higher Education, 10, 15-25

Xiao, J. (2017). Learner-content interaction in distance education: The weakest link in interaction research. Distance Education, 38(1), 123-135.

Yu, A. Y., Tian, S. W., Vogel, D., \& Kwok, R. (2010). Can learning be virtually boosted? An investigation of online social networking impacts. Computers and Education, 55(4), 1494-1503. 